\title{
Le monastère de Rila : incarnation du passé national bulgare
}

Monastery of Rila: Incarnating Bulgarian National Memory

\section{Nikolai Voukov}

\section{(2) OpenEdition}

\section{Journals}

Édition électronique

URL : http://journals.openedition.org/etudesbalkaniques/112

ISSN : 2102-5525

\section{Éditeur}

Association Pierre Belon

\section{Édition imprimée}

Date de publication : 1 janvier 2005

Pagination : 177-179

ISBN : 2-910860-05-1

ISSN : $1260-2116$

\section{Référence électronique}

Nikolai Voukov, "Le monastère de Rila : incarnation du passé national bulgare », Études balkaniques [En ligne], 12 | 2005, mis en ligne le 01 mai 2006, consulté le 19 avril 2019. URL : http:// journals.openedition.org/etudesbalkaniques/112

Ce document a été généré automatiquement le 19 avril 2019

Tous droits réservés 


\title{
Le monastère de Rila : incarnation du passé national bulgare
}

Monastery of Rila: Incarnating Bulgarian National Memory

\author{
Nikolai Voukov
}

1 Fondé comme centre de vie érémitique sous le règne du tzar Petar, le monastère de Rila devint une des bases spirituelles de l'État bulgare au cours des différentes périodes de son existence et joua un rôle décisif dans la vie culturelle pendant plus de six siècles. Étant l'un des plus importants établissements monastiques de l'espace bulgare, Rila a nourri l'identité nationale au cours de périodes de gloire et d'épreuve et a joué un rôle déterminant dans la construction de la renaissance bulgare aux XVIII ${ }^{\mathrm{e}}$ et XIX ${ }^{\mathrm{e}}$ siècles. Assumant progressivement des fonctions qui dépassaient de loin son rôle d'institution religieuse, il incarna régulièrement une identification symbolique de la religion, de l'appartenance ethnique, du destin historique et continua à imposer cette relation comme un idéal absolu.

2 Le rôle du monastère comme place-forte de l'esprit bulgare fut bien tracé dès l'époque de sa fondation, près du lieu où saint Ivan de Rila avait abrité sa vie ascétique. Après la mort $\mathrm{du}$ saint, ses reliques attirèrent largement la vénération des fidèles, ce qui justifia le projet d'établir un complexe monastique sur sa tombe et signala le début de la réputation légendaire de saint Ivan comme protecteur du peuple bulgare. Cette idée fut reprise et précisée après que la Bulgarie fut tombée sous la domination byzantine; au panthéon des conquérants byzantins les Bulgares opposèrent alors leur propre saint. Après la restauration du royaume de Bulgarie, en 1185, afin de sanctifier le pouvoir royal et de consolider la légitimité successorale, les monarques du second royaume bulgare transférèrent les reliques de saint Ivan dans la cité royale de Tirnovo. Par la suite, au XIV ${ }^{\mathrm{e}}$ siècle, époque où les Ottomans entreprenaient la conquête des Balkans, le saint fut à nouveau la principale figure tutélaire à prier pour la protection des Bulgares en temps d'invasion. 
3 Une des premières mesures prises pour restaurer le monastère et renforcer son autorité après l'invasion ottomane fut le retour des reliques de saint Ivan de la capitale dévastée à Rila, en 1469. Concernant le saint patron des Bulgares, la translation avait un caractère à la fois religieux et patriotique; elle fut perçue comme un grand événement par la population tout entière. Elle réveilla l'esprit de libération, fortifia la foi du peuple et lui rappela le saint protecteur qui soutiendrait les Bulgares sous la domination ottomane. La translation des restes de saint Ivan ouvrit la voie au rôle du monastère pendant les quatre siècles suivants : être un lieu où la mémoire du passé bulgare restait vivante et où elle était l'instrument de la lutte contre l'oppression politique et religieuse.

Rila parvint à préserver ce qui subsistait de la tradition culturelle médiévale en enrichissant de nombreuses œuvres littéraires et artistiques le fonds de chefs-d'œuvre des époques révolues. En termes politiques, le monastère déploya une activité diplomatique intense en direction de la Serbie, de la Russie, de la Roumanie et de la Grèce et soutint la cause commune des Slaves et des Orthodoxes dans leur lutte pour la libération nationale. De plus, grâce aux efforts du fondateur de l'enseignement laïc en Bulgarie -Néophyte de Rila qui fut par deux fois abbé de ce monastère- Rila devint également un établissement scolaire où des enseignants et des membres du clergé étaient formés pour répondre aux besoins de la future nation.

5 Aux XVIII ${ }^{e}$ et XIX ${ }^{e}$ siècles, l'émergence croissante de la conscience nationale des Bulgares et leur volonté de l'affirmer au moyen de la religion et de la culture eut un écho dans l'ambitieuse restauration du monastère accomplie pour l'essentiel entre 1816 et 1870 . Au cours de cette époque l'église principale, dédiée à la Nativité de la Vierge fut construite, cinq églises et chapelles bâties autour du monastère et celui-ci fut entouré par une énorme muraille digne d'une forteresse. La reconstruction fut un geste symbolique majeur visant à évoquer, affirmer et réunir la nation. Dans de nombreuses villes bulgares, des donateurs contribuèrent financièrement à la rénovation du monastère, illustrant ainsi l'engagement de toute la population en faveur du berceau de l'esprit et de l'identité bulgares. Le vaste complexe monastique, avec ses trois cents salles, son église principale spacieuse et ses nombreuses églises secondaires richement décorées révéla le sentiment renforcé de patriotisme et de fierté des Bulgares à l'époque de la renaissance nationale. Les activités pédagogiques, religieuses et politiques de Rila soutenaient et illustraient toutes trois les domaines majeurs de l'action politique et culturelle: la lutte pour l'indépendance de l'État bulgare, pour son indépendance religieuse par rapport au patriarcat grec et pour l'enseignement laïque en langue populaire bulgare. En termes de programme architectural et artistique, cette vocation fut bien reflétée par la création de nombreux ensembles voués à l'éducation, dans l'élaboration visuelle d'un véritable panthéon de saints bulgares et dans les grandes lignes de la conception esthétique du projet, le monastère était conçu comme une forteresse résistant à l'oppression politique et spirituelle.

6 Des architectes de renom, des artistes et des sculpteurs sur bois prirent part à la mise en forme artistique du programme, riche de fascinantes réalisations dans le domaine de la peinture d'icônes, de la peinture murale et du décor des iconostases. Révélant une approche réaliste moderne, une liberté de création et une recherche poussée de l'identité régionale et nationale, le monastère en tant qu'œuvre d'art illustre le passage de formes traditionnelles d'images religieuses à un art décoratif influencé par l'idéal de la renaissance nationale. Le programme iconographique inclut ainsi non seulement des thèmes religieux et moraux, mais aussi des scènes à sujet politique et patriotique. Ce 
vigoureux pathos civil envahit aussi les icônes et les peintures murales avec des portraits de saints nationaux canonisés, des portraits de donateurs, des portraits de pionniers de l'histoire religieuse et civile bulgare. La présence de saints russes et slaves n'est pas moins éclairante: elle affirme l'unité du peuple slave et la Slavia Orthodoxa, opposée à l'oppression ottomane et à l'expansionnisme religieux grec. De manière ostensible, les armoiries de divers états slaves de l'époque médiévale furent largement reproduites tant dans les chefs-d'œuvre de la peinture murale que dans ceux de la sculpture sur bois. Il est également intéressant de remarquer que les moines de Rila ne craignirent pas de faire passer à la postérité jusqu'aux "nouveaux martyrs", mis à mort par les Turcs comme défenseurs de la foi chrétienne et de l'identité nationale. Un appel non déguisé à préserver l'identité nationale dans des temps difficiles d'oppression religieuse et politique était répercuté par les nombreuses inscriptions en langue bulgare moderne qui accompagnaient divers éléments du décor.

Dans son aspect XIX ${ }^{e}$ siècle toujours préservé aujourd'hui, le monastère de Rila affiche clairement la traduction en termes architecturaux et artistiques de l'idéologie de la régénération nationale. Cette traduction s'exprime à la fois par les éléments architecturaux (coupoles, murs, arcades et voûtes) dont la grandeur entend révéler une confiance revivifiée en la patrie et par le contenu nouveau introduit par le décor interne dans les sujets et thèmes religieux traditionnels. Manifeste de la renaissance de la nation après des siècles d'occupation, les activités du monastère aussi bien que son expression artistique ont diffusé des images chargées de sens du passé bulgare, mais aussi les promesses d'un avenir réinventé au sein d'un état indépendant. Toute l'histoire du monastère, faite de vicissitudes et de reconstructions, a offert un exemple éloquent de la résistance aux épreuves et de la résurrection, dépeintes comme des éléments récurrents de l'histoire nationale. Ces notions ont été rapidement transposées dans le discours politique, soulignant le rôle de Rila comme pierre angulaire du développement de l'idéologie nationale au XIX siècle. Logiquement le monastère devint une référence majeure lors de la création de l'état bulgare moderne, après la libération et acquit le statut de monument national vénéré qu'il conserve encore aujourd'hui.

\section{RÉSUMÉS}

Consacré à saint Ivan de Rila, figure tutélaire des Bulgares contre tout envahisseur, le monastère a joué un rôle central dans l'époque de "renaissance bulgare» des XVIII ${ }^{\mathrm{e}}$ et XIX ${ }^{\mathrm{e}}$ siècles. Le complexe monastique fut perçu comme un lieu hautement symbolique, à la fois par son rayonnement culturel et par son accomplissement artistique (qui a servi ensuite comme modèle pour forger une architecture identitaire).

Dedicated to Holy Ivan of Rila - a protector of Bulgarians against invaders - the monastery played a key role during the "Bulgarian Renaissance" $\left(18^{\text {th }}-19^{\text {th }}\right.$ c.). It was a highly symbolic place because of its cultural influence and its artistic features, which were later used in order to forge an identity architecture. 


\section{AUTEUR}

\section{NIKOLAI VOUKOV}

Académie des Sciences de Bulgarie, Sofia 